\title{
CLASSIFICAÇÃO DO CALCÁRIO DA REGIÃO DO CARIRI ORIENTAL PARAIBANO USADO NA PRODUÇÃO DE CARBONATO DE CÁLCIO
}

\author{
ROMÁRIO DIAS MOURA ${ }^{1}$, Dr $^{\mathrm{a}}$ NEYLIANE COSTA DE SOUZA ${ }^{2}$, Dr $^{\mathrm{a}}$ MÁRCIA RAMOS LUIZ ${ }^{2}$ \\ ${ }^{1}$ Universidade Estadual da Paraíba, Departamento de Química \\ ${ }^{2}$ Universidade Estadual da Paraíba, Departamento de Engenharia Sanitária e Ambiental \\ E-mail para contato: marciarluiz@cct.uepb.edu.br
}

\begin{abstract}
RESUMO - O calcário é a principal matéria prima na produção de carbonato de cálcio que consiste no processo de moagem de rochas calcárias. O carbonato de cálcio é classificado de acordo com o tipo de rocha que o originou e isso é verificado através de análises físico-químicas. As amostras analisadas foram coletadas e cedidas por uma empresa da cidade de Campina Grande - PB que possui duas minas de extração de calcário na região do cariri oriental da Paraíba, sendo uma na cidade de Boa Vista e outra em Caraúbas. Os resultados mostram a existência de diferentes tipos de calcários em uma mesma microrregião, pois as amostras coletadas da mina de Boa Vista são classificadas como rochas calcíticas, com teores de óxido de cálcio em torno de $52 \%$ e óxido de magnésio de aproximadamente 1,3\%. As amostras oriundas da mina de Caraúbas são classificadas como rochas dolomíticas com teores de óxido de cálcio e de magnésio relativamente mais próximos um dos outros, $32 \%$ e $20 \%$, respectivamente.
\end{abstract}

\section{INTRODUÇÃO}

O cariri oriental paraibano é uma das regiões mais áridas e secas do Brasil. Apresenta um solo composto em sua maior parte por rochas sedimentares que se formaram a partir da precipitação de materiais gerados por microrganismos vivos ou pela evaporação da água do mar que ao se evaporar deposita diferentes minerais que também dão origem a esse tipo de rochas.

Os calcários são as rochas sedimentares carbonatadas mais conhecidas e comuns que existem. Elas são compostas principalmente de carbonato de cálcio e de magnésio, podendo conter ainda pequenas quantidades de outros minerais como: ferro, alumínio, silicatos e argilas. É encontrado extensivamente em todos os continentes e é extraído de pedreiras, de depósitos que variam em idade, desde o Pré-Cambriano até o Holoceno e representa aproximadamente $15 \%$ de todas as rochas sedimentares existentes na crosta terrestre (SAMPAIO e ALMEIDA, 2009). Essas rochas são classificadas de acordo com a sua composição química, mais precisamente, em função dos teores totais de Óxido de Cálcio e Óxido de Magnésio, determinados através de titulações complexométricas. Muitos íons metálicos formam complexos estáveis. A formação destes complexos 


\section{9 a 22 de outubro de 2014 \\ Florianópolis/SC}

serve como base para a titulação complexométrica de uma variedade de íons metálicos (BACCAN, 2001). O cálcio e o magnésio pertencem à família dos metais terrosos, e

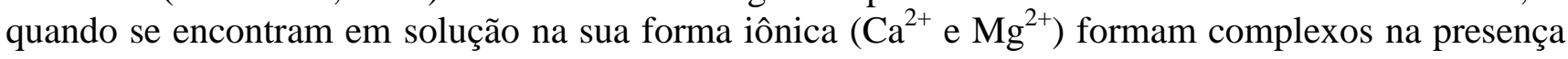
de um agente complexante como o ácido etilenodiaminotetraacetico (EDTA).

A classificação dos calcários é de grande importância, principalmente para a indústria de beneficiamento. Para antes de ser dada qualquer finalidade a rocha deve-se determinar o tipo de calcário com que se está trabalhando, para garantir que ele seja aplicado de forma correta e impeça que resultados indesejados sejam obtidos.

A indústria de beneficiamento de calcário tem grande relevância no mercado mundial, pois não há nenhuma outra rocha com uma variedade de uso tão ampla quanto esse mineral. A produção de carbonato de cálcio trata-se de um processo relativamente simples se comparado a outros segmentos industriais. É constituído de quatro operações unitárias: desmonte das rochas, britagem, peneiramento, e moagem.

O calcário na forma de rocha, ou seja, antes de ser moído, é obtido de pedreiras através do uso de explosivos para retirada. É usado principalmente na fabricação de cal através do processo de decomposição térmica conhecido como calcinação, que possibilita a obtenção da cal virgem, usada na metalurgia como aglomerante, ou ainda na produção da cal hidratada após a adição de água, usada principalmente na construção civil.

Após o processo de moagem, ele é aplicado na indústria cimenteira, contribuindo com cerca de $80 \%$ da composição do cimento. Além disso, tem importante atuação no barateamento de inúmeros produtos como: tintas, polímeros, ração animal, papel, vidro, cerâmica e no tratamento de água. Tais produtos chegam a ter uma redução de até $30 \%$ do seu preço final, em função do uso do carbonato de cálcio como material de carga.

As tendências tecnológicas no processamento do calcário para fins industriais têm focado na otimização dos processos, especialmente na caracterização das rochas utilizadas, na moagem e classificação do produto. Os principais avanços ocorreram nos projetos dos circuitos, nos equipamentos de moagem e na classificação ultrafina do material moído. Houve um rápido avanço na área de informática e os equipamentos analíticos passaram a oferecer maior precisão e baixo custo na medição do tamanho de partículas, reologia, alvura e outras propriedades físicas.

Entretanto, na região do cariri oriental da Paraíba, ainda se faz uso de recursos poucos modernos de extração e de beneficiamento do calcário, isso pode ser observado pelo fato da maioria das empresas instaladas na localidade, serem altamente dependentes da mão-de-obra local, que por sua vez é mal remunerada com pequenos salários e altas jornadas de trabalho em condições inapropriadas para a realização do processo.

O objetivo desta pesquisa é classificar o calcário existente na região do Cariri Oriental Paraibano usado na produção de carbonato de cálcio. 


\subsection{O calcário}

Calcário deriva-se do latim calcarius que significa "o que contém cal". São rochas que apresentam em sua composição química dominância do carbonato de cálcio, cuja origem, orgânica em prevalência, está associada às carapaças e esqueletos fósseis ou organismos vivos e por precipitação química (RODRIGUES e FONSECA, 2009). Existem vários tipos de calcários, sendo os mais comuns os calcíticos, os magnesianos e os dolomíticos. São classificados e diferenciados de acordo com os teores de óxido de cálcio e de magnésio que apresentam em sua composição, conforme a Tabela 1.

Tabela 1 - Classificação do Calcário de Acordo com os Teores de Óxido de Cálcio e de Magnésio

\begin{tabular}{|c|c|c|}
\hline \multicolumn{3}{|c|}{ CLASSIFICAÇÃO DOS CALCÁRIOS } \\
\hline Tipo & \% de Óxido de Cálcio $(\mathrm{CaO})$ & \% de Óxido de Magnésio $(\mathrm{MgO})$ \\
\hline Calcítico & 45 a 55 & $<5$ \\
\hline Magnesiano & 31 a 32 & $5 \mathrm{a} 12$ \\
\hline Dolomítico & 25 a 45 & $>12$ \\
\hline
\end{tabular}

Fonte: INCAPER (2007).

O território do Cariri Oriental encontra-se na porção centro-sul do Estado, em direção ao entalhamento do rio Paraíba, essa região é composta por quatorze municípios que juntos possuem uma população de 80.851 mil habitantes que ocupam uma área de $8.214 \mathrm{Km}^{2}$ IBGE (2007). Os solos dessa região são em geral, rasos e pedregosos, com espessura inferior a $50 \mathrm{~cm}$, possuem uma estreita camada de material terroso sobre a rocha, ocorrendo mais frequentemente, em áreas de relevo acidentado. No mapeamento da região do cariri oriental da Paraíba feito pelo governo federal é possível observar a predominância do calcário e da bentonita como os principais minerais existentes na região (PLANO TERRITORIAL DE DESENVOLVIMENTO RURAL SUSTENTÁVEL, 2010).

\subsection{Beneficiamento do calcário}

O processo de beneficiamento de calcário é constituído basicamente de quatro operações unitárias: desmonte das rochas com o uso de explosivos, britagem e peneiramento feitos respectivamente, através de britadores de mandíbula e de peneiras com aberturas específicas e moagem realizada por moinhos geralmente de rolos ou de pêndulos. Esse processo é feito visando o seu aproveitamento, nos mais diversos ramos das indústrias que fazem uso deste mineral como matéria prima. É importante ressaltar que o calcário já é o carbonato de cálcio propriamente dito, pois este é o principal componente desse mineral, a diferença entre os dois é dada especialmente pelo tamanho de suas partículas ainda quando rocha e após o seu beneficiamento onde se apresenta na forma de pó.

O processo de extração e beneficiamento da rocha calcária tem como objetivo produzir e comercializar calcário, visando atender à demanda existente desta matéria-prima nas indústrias de transformação especialmente para produção da cal, do cimento e de tintas, que são os segmentos que fazem uso da maior parte do calcário beneficiado atualmente. As minas de calcário, em todo o mundo, 


\section{9 a 22 de outubro de 2014 \\ Florianópolis/SC}

são lavras a céu aberto, principalmente por motivos de custos mais reduzidos. Elas são comumente chamadas de pedreiras, apesar de que, por razões técnicas, ambientais ou de escala de produção, algumas utilizam a lavra subterrânea.

As principais etapas da lavra de calcário a céu aberto incluem: remoção do capeamento, perfuração, desmonte por explosivos e transporte até a usina de processamento. A remoção do capeamento é o elemento-chave no custo da lavra a céu aberto. Para cada operação ou situação, há uma razão estéril/minério economicamente viável. A escala de produção é responsável pela viabilidade econômica de várias minas, especialmente tendo em vista os produtos serem de valor agregado relativamente baixo. A seleção dos equipamentos varia com a particularidade de cada operação, capacidade de produção, tamanho e forma do depósito, distância de transporte, estimativa da vida útil da mina, localização em relação aos centros urbanos e fatores socioeconômicos (SAMPAIO e ALMEIDA, 2009). O carbonato de cálcio é obtido através de quatro processos básicos aplicados ao calcário, também conhecidos como operações unitárias de processamento, conforme mostra a Figura 1.

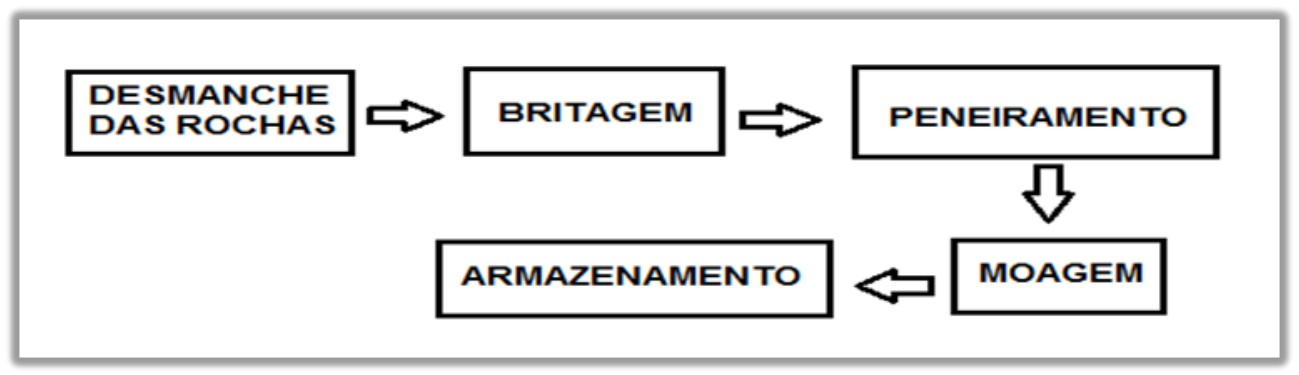

Figura 1 - Fluxograma da Produção do Carbonato de Cálcio.

\section{MATERIAIS E MÉTODOS}

Todas as análises deste estudo foram realizadas em triplicatas no laboratório de controle de qualidade em uma empresa de beneficiamento de calcário localizada na cidade de Campina Grande PB, que forneceu as amostras. A mesma foi capaz de viabilizar e oferecer as condições necessárias para a realização de análises físico-química exigidas pela a Associação Brasileira de Normas Técnicas (ABNT).

As amostras foram coletadas em três semanas distintas, durante o mês de novembro de 2013. A cada semana foram retiradas duas amostras diretamente dos caminhões, uma amostra referente ao carregamento vindo da mina de Boa Vista - PB e outra referente ao carregamento proveniente da mina de Caraúbas - PB. Após a coleta, as amostras foram devidamente limpas com o auxílio de escovas para retirar alguns minerais como areia e argila presentes na superfície do calcário, em seguida foram trituradas como a ajuda de um almofariz e um pistilo até se obter um pó (carbonato de cálcio) suficientemente fino. Para garantir que o calcário foi devidamente pulverizado realiza-se ensaios granulométricos com peneiras, de acordo com a NBR 9289:2000 da ABNT, no ano de 2000, que classificou a amostra de carbonato de cálcio com malha \# 200 (partículas com 0,075 mm de diâmetro) que é a especificação mínima de tamanho que as partículas das amostras devem apresentar 
para uma satisfatória reação nos ensaios para determinação da composição química do calcário. As análises físico-químicas foram executadas de acordo com a normativa NBR 6473:2003 da ABNT que descreve todo o procedimento para determinação da composição química de cales, mas que também pode ser aplicado ao carbonato de cálcio na determinação da sua composição.

\section{RESULTADOS E DISCUSSÃO}

\subsection{Análises Granulométricas das Amostras}

A peneira de malha \# 200 foi utilizada para classificar granulometricamente as amostras e garantir que elas não possuam partículas com diâmetros maiores que $0,075 \mathrm{~mm}$. A Tabela 2 mostra as porcentagens de resíduos retidos em cada peneira após a execução do ensaio por via úmida nas amostras recolhidas das minas de Boa Vista e Caraúbas.

Tabela 2 - Resultado da Análise Granulométrica das Amostras

\begin{tabular}{|c|c|c|c|c|c|c|}
\hline \multicolumn{7}{|c|}{ RETENÇÃO (\%) } \\
\hline Mina & \multicolumn{3}{|c|}{ Boa Vista } & \multicolumn{3}{|c|}{ Caraúbas } \\
\hline Peneiras & Teste 01 & Teste 02 & Teste 03 & Teste 01 & Teste 02 & Teste 03 \\
\hline $0,600 \mathrm{Mm}\left(\mathrm{N}^{\circ} 30\right)$ & 0,0 & 0,0 & 0,0 & 0,0 & 0,0 & 0,0 \\
\hline $0,075 \mathrm{Mm}\left(\mathrm{N}^{\circ} 200\right)$ & 0,0 & 0,0 & 0,0 & 0,0 & 0,0 & 0,0 \\
\hline
\end{tabular}

De acordo com os resultados apresentados na Tabela 2, às amostras submetidas aos ensaios granulométricos não apresentam partículas maiores que $0,075 \mathrm{~mm}$, sendo assim podem ser utilizadas para as determinações de sílica mais resíduos insolúveis, óxidos de cálcio total e óxido de magnésio total. Esse resultado torna desnecessário que seja realizado por via seca, pois como já dito anteriormente ele é realizado de acordo com as normas na ABNT, o que garante maior confiabilidade a análise.

\subsection{Classificação do Calcário da Mina de Boa Vista - PB}

Boa Vista é um Município localizado no Cariri oriental paraibano que faz parte da Região Metropolitana de Campina Grande - PB. Possui em seu território grande reservas de bentonita e calcário o que já tem atraído olhares de grandes empresas de mineração e de produção de cimento.

A empresa onde ocorreu a pesquisa possui uma mina de extração de calcário localizado na cidade de Boa Vista. As rochas vindas dessa mina, assim como as das demais, passam por uma série de análises para que sejam classificadas de acordo com os teores de óxido de cálcio e de magnésio. A Tabela 3 mostra os teores totais de óxido de cálcio e de magnésio presentes em amostras de rochas de calcário proveniente da mina de Boa Vista analisadas. 
Tabela 3 - Determinação dos Teores Totais de Óxido de Cálcio e de Magnésio Presente no Calcário da Mina de Boa Vista - PB

\begin{tabular}{|l|r|r|r|r|r|r|}
\hline \multicolumn{7}{|c|}{ CALCÁRIO DA MINA DE BOA VISTA - PB } \\
\hline Análise & \multicolumn{3}{|c|}{$\%$ de Óxido de Cálcio } & \multicolumn{3}{c|}{$\%$ de Óxido de Magnésio } \\
\hline Amostra & \multicolumn{1}{|c|}{ Teste 01} & \multicolumn{1}{|c|}{ Teste 02} & \multicolumn{1}{|c|}{ Teste 03} & \multicolumn{1}{|c|}{ Teste 01} & \multicolumn{1}{c|}{ Teste 02} & \multicolumn{1}{c|}{ Teste 03 } \\
\hline BV-01 & 52,76 & 52,69 & 52,73 & 0,97 & 1,01 & 1,05 \\
\hline BV-02 & 51,96 & 52,08 & 52,03 & 1,55 & 1,42 & 1,62 \\
\hline BV-03 & 52,01 & 51,98 & 52,98 & 1,36 & 1,36 & 1,34 \\
\hline Média & 52,24 & 52,25 & 52,58 & 1,29 & 1,26 & 1,33 \\
\hline
\end{tabular}

Onde:

BV- amostra de calcário da mina de Boa Vista 01, 02 e 03 - correspondem as semanas coletadas.

De acordo com a Tabela 1, pode-se verificar que os resultados apresentados na Tabela 3 indicam que o calcário extraído da mina localizada na cidade de Boa Vista - PB deve ser classificado como calcítico, por apresentar teor de óxido de cálcio total em torno de $52 \%$ e teor de óxido de magnésio total em torno de 1,3\% de acordo com as análises realizadas.

\subsection{Classificação do Calcário da Mina de Caraúbas - PB}

Caraúbas, Município do Estado da Paraíba, localizado na microrregião do Cariri Oriental. Apesar de ainda pouco explorado, possui consideráveis reservas de rochas calcárias, que pode ser utilizada tanto para a produção de carbonato de cálcio quanto no setor de desdobramento de rochas ornamentais. A empresa onde ocorreu a pesquisa possui uma mina de exploração de calcário nesse Município. A Tabela 4 mostra os teores de óxido de cálcio e magnésio presentes em amostra de rochas de calcário provenientes da mina de Caraúbas e analisadas unicamente para a realização deste estudo.

Tabela 4 - Determinação dos Teores Totais de Óxido de Cálcio e de Magnésio Presente no Calcário da Mina de Caraúbas - PB

\begin{tabular}{|l|l|l|l|l|l|l|}
\hline \multicolumn{7}{|c|}{ CALCÁRIO DA MINA DE CARAÚBAS - PB } \\
\hline Análise & \% de óxido de cálcio & \% de óxido de magnésio \\
\hline Amostra & Teste 01 & Teste 02 & Teste 03 & Teste 01 & Teste 02 & Teste 03 \\
\hline CB-01 & 33,17 & 33,15 & 33,16 & 19,29 & 19,27 & 19,27 \\
\hline CB-02 & 32,60 & 32,62 & 32,64 & 19,24 & 19,24 & 19,24 \\
\hline CB-03 & 30,92 & 30,95 & 30,95 & 20,89 & 20,92 & 20,92 \\
\hline Média & 32,23 & 32,24 & 32,25 & 19,80 & 19,81 & 19,81 \\
\hline
\end{tabular}




\section{9 a 22 de outubro de 2014 \\ Florianópolis/SC}

Onde:

CB - amostra de calcário da mina de Caraúbas

Os resultados das análises realizadas nas amostras de calcário apresentados na Tabela 04 indicam que as rochas calcárias extraídas da mina da cidade de Caraúbas, devem ser classificadas como dolomita, por apresentarem teores de óxido de cálcio total em torno de $32,2 \%$ e teores de óxido de magnésio total em torno de 19,8\%, de acordo com a Tabela 1.

\section{CONSIDERAÇÕES FINAIS}

Com bases nos resultados obtidos para a classificação do calcário, pode-se afirmar que as duas minas exploradas pela empresa que disponibilizou as amostras possuem tipos de calcários diferentes, sendo a mina de Boa Vista detentora de rochas calcárias do tipo calcíticas e a de Caraúbas do tipo dolomíticas o que confere ao beneficiador do minério maiores possibilidades de mix de produtos.

O calcário da mina de Boa Vista apresenta na sua composição relevantes quantidades de sílica e resíduos insolúveis, o que indica que as rochas dessa jazida não possuem alto grau de pureza. No entanto, o calcário dessa mina demostrou ser mais rentável quando submetido a processos de decomposição térmica, pois as quantidades de dióxido de carbono $\left(\mathrm{CO}_{2}\right)$ presentes nessa rocha são menores.

Por fim, este trabalho além de cumprir seu objetivo principal, que é a classificação das rochas calcárias existentes na região do cariri oriental paraibano. Chama a atenção também ao fato de demonstrar que uma mesma microrregião considerada relativamente pequena com uma área de 8.214

$\mathrm{Km}^{2}$, apresentar diferentes tipos de calcário em quantidades consideráveis, que podem inclusive, serem exploradas comercialmente de forma mais efetiva. Essa conclusão reforça não apenas a necessidade de estudos no que diz respeito à classificação de rochas calcárias, mas também no que se refere ao controle de qualidade no beneficiamento de calcário para a produção de carbonato de cálcio ou de qualquer outro produto que utilize esse minério como matéria prima.

\section{REFERÊNCIAS}

ASSOCIAÇÃO BRASILEIRA DE NORMAS TÉCNICAS, NBR 6473:2003: Cal virgem e cal hidratada - análise química. Rio de Janeiro: ABNT, 2003.

ASSOCIAÇÃO BRASILEIRA DE NORMAS TÉCNICAS, NBR 9289:2000: cal hidratada para argamassas determinação da finura. Rio de Janeiro: ABNT, 2000.

ASSOCIAÇÃO BRASILEIRA DE NORMAS TÉCNICAS, NBR 6023: informação e documentação: referências: elaboração. Rio de Janeiro: ABNT, 2003.

BACCAN, Nivaldo. Química analítica quantitativa elementar/ Nivaldo Baccan, João Carlos de Andrade, Oswaldo E. S. Godinho e José Salvador Barone. $3^{\text {a }}$ edição- São Paulo: Edgard Blucher Instituto Mauá de tecnologia, 2001.

INSTITUTO BRASILEIRO DE GEOGRAFIA E ESTATÍSTICA - IBGE. SENSO 2007 População recenseada e estimada, segundo os municípios - Paraíba - 2007. Disponível em: 
http://www.ibge.gov.br/home/estatistica/populacao/contagem2007/contagem_final/tabela1_1_12. pdf. Acesso em: 21/02/2014. INSTITUTO CAPIXABA DE PESQUISAS, ASSISTÊNCIA TÉCNICA E EXTENSÃO RURAL INCAPER 2007.

RESUMO EXECUTIVO: PLANO TERRITORIAL DE DESENVOLVIMENTO RURAL SUSTENTÁVEL - PTDRS TERRITÓRIO DO CARIRI ORIENTAL - PB 2010. Disponível em: < http://sit.mda.gov.br/download/ptdrs/ptdrs_qua_territorio027.pdf> acesso em: 25/01/2014.

RODRIGUES, Antônio Fernando da Silva e FONSECA, David Siqueira. Cimento. 2009. Disponível em: < https://sistemas.dnpm.gov.br/publicacao/mostra_imagem> acesso em: 22/02/2014

SAMPAIO, J. A. e ALMEIDA, S. L. M. Calcário e dolomito. Disponível em: < http://www.cetem.gov.br/publicacao/CTs/CT2005-132-00.pdf> Acesso em: 29/12/2013. 